\title{
Review Article \\ Genetic and Epigenetic Mechanisms That Maintain Hematopoietic Stem Cell Function
}

\author{
Christian Kosan and Maren Godmann \\ Center for Molecular Biomedicine (CMB), Department of Biochemistry, Friedrich-Schiller-University Jena, \\ Hans-Knöll-Straße 2, 07745 Jena, Germany \\ Correspondence should be addressed to Christian Kosan; Christian.kosan@uni-jena.de \\ and Maren Godmann; Maren.godmann@uni-jena.de
}

Received 1 July 2015; Revised 3 September 2015; Accepted 9 September 2015

Academic Editor: Kevin D. Bunting

Copyright (C) 2016 C. Kosan and M. Godmann. This is an open access article distributed under the Creative Commons Attribution License, which permits unrestricted use, distribution, and reproduction in any medium, provided the original work is properly cited.

\begin{abstract}
All hematopoiesis cells develop from multipotent progenitor cells. Hematopoietic stem cells (HSC) have the ability to develop into all blood lineages but also maintain their stemness. Different molecular mechanisms have been identified that are crucial for regulating quiescence and self-renewal to maintain the stem cell pool and for inducing proliferation and lineage differentiation. The stem cell niche provides the microenvironment to keep HSC in a quiescent state. Furthermore, several transcription factors and epigenetic modifiers are involved in this process. These create modifications that regulate the cell fate in a more or less reversible and dynamic way and contribute to HSC homeostasis. In addition, HSC respond in a unique way to DNA damage. These mechanisms also contribute to the regulation of HSC function and are essential to ensure viability after DNA damage. How HSC maintain their quiescent stage during the entire life is still matter of ongoing research. Here we will focus on the molecular mechanisms that regulate HSC function.
\end{abstract}

\section{Introduction}

Hematopoiesis is the development of all mature blood cell lineages that emerge from multipotent hematopoietic stem cells (HSC) in the bone marrow. The human hematopoietic system produces around $10^{12}$ cells very day. HSC have the ability to differentiate into all hematopoietic lineages but also retain their self-renewal capacity [1]. HSC are located in stem cell niches in the bone marrow that provide signals to maintain stem cell quiescence. Cell intrinsic mechanisms like transcription factor networks and epigenetic regulations have been shown to regulate the balance between self-renewal and differentiation [2]. Under homeostatic conditions HSC cycle very infrequently and stay mainly in $\mathrm{G}_{0}$ [3]. This has been shown by two different long-term label-retention assays $[4,5]$. These data point to very slow cycling (quiescent) HSC that cycle only every 145 days, which results in about 5 cell divisions per life time [5]. Wilson and coworkers could also show that dormant HSC can be activated by injury and that this is reversible; at least some activated HSC can switch back into a quiescent state. In addition, Takizawa and coworkers could show that life-long multilineage repopulation potential can also be detected in faster cycling cell populations as described for quiescent HSC [4-6]. Interestingly, this faster cycling population can also slow down over time, indicating that divisional activity does not necessarily lead to a loss of HSC function. This contradiction to the work from Foudi and Wilson might be caused by technical differences mainly in FACS-based cell analysis as well as in different in vivo tracking systems and different transplantation assays [6]. Furthermore, Takizawa and colleagues could also show that HSC can be efficiently activated using LPS. This is of particular interest to understand how HSC can be activated upon stress.

During differentiation, HSC progressively lose their ability to self-renew and gain lineage specificity of the different hematopoietic lineages [7].

To ensure their life-long functionality, HSC have to be protected against any type of DNA damage. Recent work points to a unique mechanism of how HSC respond to DNA damage (DDR). In quiescent HSC, the response to DNA damage is regulated by a strong induction of p53 and 
the upregulation of $\mathrm{p} 21$, whereas faster cycling multipotent progenitors (MPP) respond with apoptosis [8]. This review focuses on recent findings of how HSC maintain their stem cell capacity by transcriptional regulation as well as epigenetic modifications and, furthermore, how HSC deal with DNA damage upon irradiation and during aging.

\section{Hematopoietic Stem Cells}

The hematopoietic system consists of two major lineages: on the one hand the myeloid lineage and on the other hand the lymphoid lineage. The myeloid lineage includes the cells of the humoral immune response and erythroid cells. The lymphoid lineage consists of $\mathrm{B}$ and $\mathrm{T}$ cells, the cells of the adaptive immune system, and natural killer (NK) cells. All cellular compartments of the hematopoietic system are derived from hematopoietic stem cells [7]. HSC develop into all hematopoietic lineages following a strict hierarchical order. During this process they gradually lose their selfrenewal capacity and gain lineage specificity. Quiescent longterm HSC (LT-HSC) mainly reside in distinct areas of the bone marrow, the so-called stem cell niche [9]. Upon activation LT-HSC leave this niche and migrate towards the blood vessels. Here, they undergo asymmetric cell division, which produces again one LT-HSC and one short-term HSC (ST-HSC) that subsequently differentiates into a multipotent progenitor cell. ST-HSC and MPP still have the potential to differentiate into all hematopoietic lineages but they have lost their self-renewal capacity [10]. Further differentiation into a more committed progenitor is a stepwise process. The common myeloid progenitors (CMP) are restricted to the myeloid lineage and differentiate into granulocyte-monocyte progenitors (GMP) and megakaryocyte-erythrocyte progenitors (MEP). MEP and GMP give rise to erythrocytes and platelets or granulocytes and macrophages, respectively. Lymphoid primed multipotent progenitors (LMPP) give rise to common lymphoid progenitors (CLP), which, in turn, produce progenitors of the lymphoid cells and NK cells. LMPP also have the potential to differentiate into granulocyte-monocyte progenitors (GMP) but have an impaired capacity to develop into cells of the megakaryocytic or erythroid lineages [11-15].

Several signaling pathways have been shown to affect stem cell function like BMP-, Hedgehog-, Notch-, Wnt-, and TGF- $\beta$ signaling pathways. These pathways transduce signals from the microenvironment to activate cell intrinsic signaling cascades to regulate HSC self-renewal, differentiation, apoptosis, senescence, and proliferation. Their function differs with the location of the HSC in the bone marrow niche and the developmental stage and indicates the importance of a tight control of these signaling pathways.

\section{The Microenvironment of the Bone Marrow-Hematopoietic Stem Cell Niche}

Proper HSC function is mandatory to regulate the balanced outcome of all hematopoietic cells and to maintain homeostasis. During adult life HSC are located in the bone marrow niche, where they are in loose contact with stroma cells that regulate the balance of HSC self-renewal and differentiation
[9]. The niche provides a complex environment that supports stem cell function by providing cytokines, growth factors, oxygen tension, and nutrients [16-18] and, moreover, the niche is absolutely critical for stem cell quiescence. Distinct cell types in the stem cell niche, like osteoblast and osteoclast, provide this microenvironment for stem cell maintenance.

Several molecular mechanisms have been described to be essential for perpetuation of HSC quiescence. A tight regulation of signaling networks, cytokines and cytokine receptors, adhesion molecules, matrix proteins, and concentration gradients of some chemical molecules are involved in these processes. The hematopoietic stem cell niche is characterized by an intrinsic dynamic to regulate quiescence, self-renewal, and proliferation of hematopoietic stem cells and consists of several cell types that are crucial for HSC quiescence and has been discussed recently [19, 20]. Several chemokines and signaling pathways have been identified to control HSC integrity in the stem cell niche.

CXCL12 is a key niche factor that regulates HSC retention in the niche on the one hand and HSC quiescence and multilineage potential [21]. Deletion of CXCR4, the receptor for CXCL12, results in a substantial loss of HSC and demonstrates an essential role of CXCL12-CXCR4 signaling in maintaining HSC quiescence [22]. Furthermore Notch- and Wnt $/ \beta$-catenin signaling as well as TGF- $\beta$ signaling pathways are discussed to be important regulators of HSC function. For example, Wnt/ $\beta$-catenin signaling provides essential signals to ensure quiescence and preserves self-renewal capacity [23]. However, inactivation of $\beta$-catenin and $\gamma$-catenin does not affect HSC function or hematopoiesis in general (Figure 1) $[24,25]$.

There are some controversial findings, which might result from different experimental approaches and the complexity of the signaling pathways. This topic is extensively discussed in an excellent review from Mendelson and Frenette [19].

\section{Transcription Factor Networks in HSC}

During development, HSC follow specific differentiation programs that are distinct for embryonic and adult development [26]. Transcription factors play a key role in regulating these differentiation programs besides maintaining stem cell quiescence in the adult organism. In order to meet different requirements, these transcription factors act in huge regulatory complexes, often with different binding partners. However, there are about 50 different transcription factors that have been shown to affect HSC functionality and behavior throughout adult life. Interestingly, many of these transcription factors are imbedded in regulatory networks that show a very high degree of connectivity. In this section, we will just focus on a selection of key transcription factors that are required for HSC production, survival, and selfrenewal.

Several key transcription factors that regulate HSC function have been identified by gene targeting experiments (Figure 1) [27]. But due to the different requirements during fetal and adult hematopoiesis and different knockout and experimental strategies the results obtained from these experiments are sometimes not easy to interpret. One key regulator 


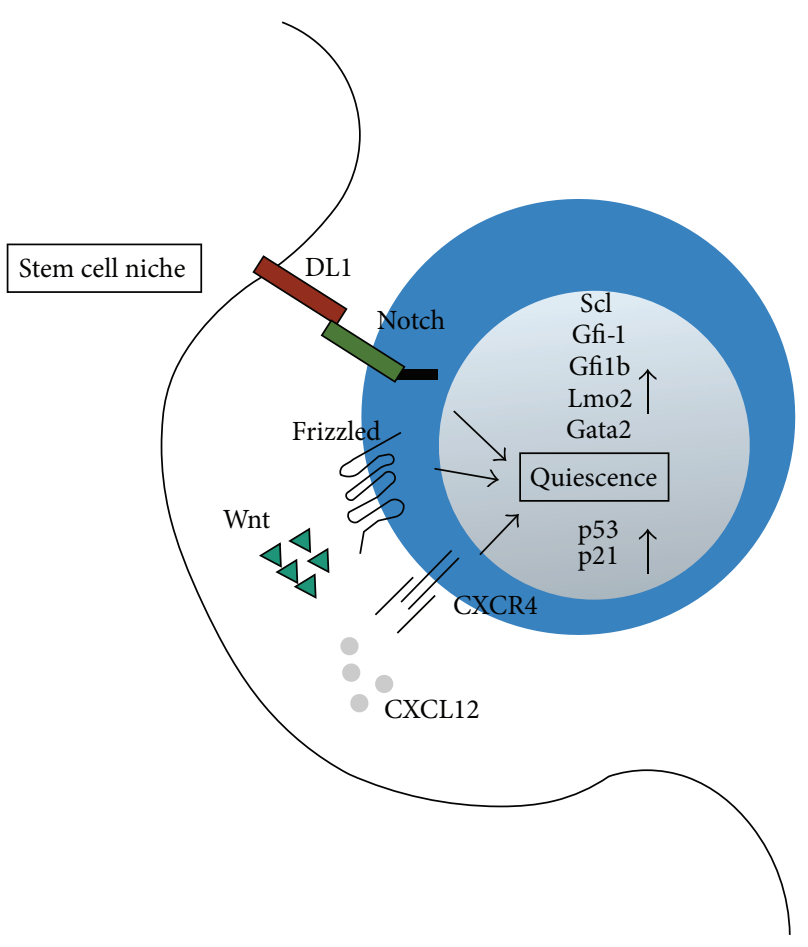

Figure 1: Hematopoietic stem cells maintain quiescence through extrinsic and intrinsic signals. The stem cell niche provides signals that regulate HSC quiescence and localization in the niche. DL1 and Notch; CXCL12 and CXCR4; and Wnt and Frizzled. HSC intrinsic transcription factors regulate signaling process to keep HSC in a quiescent stage.

of hematopoiesis is the helix-loop-helix transcription factor $\mathrm{Scl} /$ Tall. The complete ablation of $\mathrm{Scl}$ is embryonic lethal and points towards a defect in fetal HSC genesis [28, 29]. Different conditional knockout studies shed more light on the function of $\mathrm{Scl}$ in the hematopoietic system: $\mathrm{Scl}$ is essential for HSC development already at early embryonic development in the yolk sac and remains indispensable for proper megakaryocyte and erythroid development in the adult mouse $[30,31]$. Furthermore, $\mathrm{Scl}$ is also required for the regulation of quiescence and long-term potential of HSC. Surprisingly, $\mathrm{Scl}$ is not essential for self-renewal and multipotency of these cells [32]. In this study, Scl was conditionally inactivated only in the adult mouse using an inducible $\mathrm{Mx}$-Cre deleter pointing to a dominant role of Scl during embryonic development. Supporting this hypothesis, Schlaeger and coworkers could show in a Tie2-Cre-mediated knockdown that $\mathrm{Scl}$ is only required in a very tight window during fetal development [33]. Nevertheless, a more recent study showed that a reduced level of Scl impairs HSC function and that $\mathrm{Scl} / \mathrm{Tall}$ is also required for the regulation of HSC quiescence and the long-term potential of hematopoietic stem cells in the adult mouse [34]. These contradictive results might be explained by different experimental setups; further studies have to bring insights about the exact role of $\mathrm{Scl}$ in adult hematopoiesis.

However, when Scl is expressed together with LIM only protein 2 (Lmo2) and GATA binding factor 1 (Gata1),
SCL induces ectopic blood cell development, which, again, underlines the importance of Scl in HSC genesis $[35,36]$. The transcription factor Lmo2 regulates the formation of DNA-binding complexes, although Lmo2 itself does not bind directly to the DNA [37]. Gata2 regulates development as well as cell cycle progression and proliferation of hematopoietic stem and progenitor cells. Gata2 $\left(\mathrm{Gata}^{-/-}\right)$knockout mice are embryonic lethal and Gata2 $2^{-/-}$ES cells have been shown to be perturbed in the production of hematopoietic cells in chimeric mice. Moreover, HSC showed reduced responsiveness to stem cell factor (SCF) and increased apoptosis [3840].

Using conditional mouse models it has been shown that Gata2 is required for the generation of HSC at the stage of endothelial-to-hematopoietic cell transition and for HSC survival [38]. It has previously been demonstrated that Gata2 interacts with Runx1, to regulate transcription of genes relevant to hematopoietic cell development and growth [41, 42].

Interestingly, experiments done by Chen and coworkers were performed with the same Cre-recombinases (Vec-Cre and Vavl-Cre) as they have previously been used to generate a conditionally inactive form of Runx1 [43]. This revealed that the previously described concurrent function of Gata2 and Runxl is only essential in endothelial-to-hematopoietic transition (EHT) but also revealed important new insights into separate GATA2 and RUNX1 functions in hematopoietic progenitors and HSC at different developmental stages [38]. Mice deficient for Gatal die at embryonic stages E10.5-E11.5 due to a lack of red blood cells (RBCs) [44]. In contrast to Gata2, Gatal is more restricted to the erythroid and megakaryocytic lineage and HSC are almost negative for Gatal expression but ectopic expression of Gatal in HSC resulted almost exclusively in MegE-affiliated colonies [45]. This clearly points towards a lineage determining role rather than a function in HSC maintenance.

Other major regulators crucial for maintaining HSC functions are the zinc finger transcription factors growth factor independent 1 (Gfil) and growth factor independent $1 b$ (Gfilb). Gfil is expressed in several hematopoietic cells types, like myeloid and lymphoid cells, and Gfil is also expressed in HSC. Gfil (Gfil ${ }^{-/-}$) deficiency leads to severe anemia [46-50].

Hock and coworkers detected at least as many, if not more, HSC in the bone marrow of Gfil-deficient mice compared to WT mice [51]. In contrast, the group of Tarik Möröy observed strong reduction of HSC in Gfil ${ }^{-/-}$mice [50]. This might be due to different gating strategies in the FACS analysis, since both knockout strategies are pretty similar. This illustrates the difficulty and complexity of the analysis of very small cell populations like HSC.

HSC derived from $\mathrm{Gfil}^{-/-}$mice show a reduced selfrenewal capacity and a perturbed repopulation capacity after adaptive transfer in syngeneic mice $[50,51]$.

A larger number of HSC in Gfil-deficient mice were in the proliferative stages of the cell cycle, indicating that Gfil functions to restrain HSC proliferation. In conclusion, both groups suggest that the excessive proliferation of $\mathrm{Gfil}^{-/-} \mathrm{HSC}$ results in exhaustion and this leads to loss of self-renewal 
capacity. Consistent with this was a downregulation of the negative cell cycle regulator $\mathrm{p} 21^{\mathrm{Cip}}$, which is required to maintain $\mathrm{HSC}$ in $\mathrm{G}_{0}$ [51]. However, recent reports point more to a role of $\mathrm{p} 21^{\mathrm{Cip}}$ in regulating cell cycle activity during stress response rather than homeostasis (see cell cycle section) [4, 52]. That might indicate that $\mathrm{p} 21^{\mathrm{Cip}}$ downregulation is not the sole reason for the phenotype in Gfi- $1^{-/-}$mice. Moreover, it has been shown that Gfil fulfills an additional role in HSC maintenance by protecting HSC from apoptosis [53].

The transcription factor Gfilb is indispensable for embryonic and adult erythroid development, and it is highly expressed in HSC $[48,54,55]$. Conditional inactivation of Gfilb using an inducible Mx-Cre line leads to an increased frequency of HSC but a reduced quiescence [53]. However, multipotency and self-renewal capacity are not altered in these mice [53].

HSC from Gfilb deficient mice show a reduced expression of adhesion molecules, like CXCR4 and the vascular cell adhesion protein-1 (Vcam-1), which are required to retain HSC in the stem cell niche [48].

All in all, both transcription factors, Gfil and Gfilb, are essential for HSC maintenance and preserve quiescence, due to different molecular mechanisms.

The importance of a proper interaction of HSC with their niche is once more demonstrated by aberrant expression of the transcription factor c-Myc. Ectopic expression of c-Myc in HSC leads to a loss of self-renewal capacity and induces lineage differentiation due to repression of $\mathrm{N}$-cadherin and integrins. These data point to an essential role of c-Myc in regulating the balance between stem cell self-renewal and differentiation, most likely by influencing the interaction of HSC with the stem cell niche $[2,56]$.

Just to name a few more examples, Ets transcription factors like Pu.1, Erg, and Fli1, homeobox factors like HoxA9 and HoxA10, the TALE family transcription factor Meis1, and Helix-loop-Helix proteins like E2A are other essential transcription factors that are involved in HSC development and maintenance. Their functions have been extensively discussed in a recent review [57]. The rising number of factors involved in HSC fate and function and recent findings that these factors act in distinct complexes add another level of complexity, which requires different approaches to get insight into the underlying molecular mechanisms. Wilson and coworkers used a Chromatin ImmunoprecipitationSequencing (ChIP-Seq) approach to identify genome-wide binding sites of ten key hematopoietic transcription factors (Scl/Tal1, Lyl1, Lmo2, Gata2, Runx1, Meis1, Pu.1, Erg, Fli1, and Gfilb) [42]. Using a multifactor ChIP-Seq approach has the advantage of a more comprehensive view of regulatory mechanism. The authors could identify new complexes directly bound to regulatory elements that are essential for specific processes in HSC. Furthermore, the authors could confirm that Runx1, Gata2, and Scl control a set of genes that are critical in regulating the balance between quiescence and self-renewal of HSC [42]. These findings give new insights into the role of each factor in its transcriptional network and might also explain the compensatory effect of some factors regulating HSC function.
To activate or repress gene expression, transcription factors recruit cofactors to their binding sites to regulate accessibility of regulatory regions. For example, Gfil and Gfilb recruit CoREST and LSD1 to the promoter regions of target genes to mediate transcriptional repression [58]. Furthermore, Gfil and Gfilb also recruit histone deacetylases (HDAC) to promoter regions of target genes to downregulate transcription [59-61]. This clearly points to a crucial role of epigenetic mechanisms in sustaining HSC quiescence and changes in epigenetic patterns might lead to changes of the genetic program and eventually HSC fate. This will be discussed in more detail in the next section.

\section{Epigenetic Modification in HSC}

Somatic cells of an individual share per se the same genetic information. What puts a face on cells and evolves them into true specialists to fulfill different body functions is an additional layer of so-called epigenetic information that is imposed on the DNA or histone proteins, for example, DNA methylation and posttranslational histone modifications. These epigenetic modifications eventually result in a defined chromatin structure and thus an "individual" gene expression pattern in a cell [62].

In the healthy adult body, only lineage-restricted, hence multipotent or unipotent, stem cells can be found. These cells are already equipped with specific sets of epigenetic marks that provide the basic information for directions of subsequent differentiation processes. The hematopoietic system provides an ideal model system to study the correlation between epigenetically directed changes in chromatin structure and gradual restriction of cell potential during differentiation, since the hematopoietic cell lineage development follows a strict hierarchical pattern emanating from a single primary source, the hematopoietic stem cell. HSC are multipotent and have the ability either to self-renew to maintain the HSC pool throughout life or to differentiate into all functional blood cells. The molecular mechanisms that actually determine hematopoietic cell fate or lineage commitment are highly complex and are not well understood today. Global gene expression analyses in combination with epigenetic profiling of hematopoietic cells at different developmental stages will provide a more comprehensive picture of cell fate decisions in hematopoiesis and thinking one step further in disease conditions. Here, the unanswered question is: What happens if the highly orchestrated establishment of epigenetic signatures in differentiating cells is disturbed?

5.1. Histone Methylation in HSC. Covalent histone modifications are crucial for virtually all cellular processes that modulate the access to the genomic DNA, like transcription, DNA replication, DNA repair, meiosis, or compaction of DNA. They directly influence the structure of nucleosomes or generate a signaling platform to recruit so-called "reader" proteins that mediate downstream effects. Over 100 different histone modifications have been identified to date, with more being expected to be discovered in the near future (for review see $[62,63])$. 
One classical posttranslational histone modification mark is the methylation of lysine or arginine residues. Histone methylation is a reversible process: methyl marks are established by histone methyltransferases, so-called "writers," and removed by histone demethylating enzymes, termed "eraser" [64]. Thus, a great variety of histone methylation states is created and different methylation states are linked to different biological processes. The role of histone methylation states in fine-tuning gene expression has been well studied and key findings in cell fate decisions have been made in embryonic stem cells (ESC) as well as in HSC [65-67]. Here, we focus on recent advances that link regulation of gene expression in HSC fate decisions to histone methylation events that occur on histone $\mathrm{H} 3$ lysine 4 (H3K4), histone H3 lysine 9 (H3K9), and histone $\mathrm{H} 3$ lysine 27 (H3K27).

A phenomenon firstly described in embryonic stem cells (ESC) is the appearance of bivalent chromatin, which refers to distinct gene regulatory regions that are simultaneously occupied with counteracting marks. Mostly, key developmental genes that are poised in stem cells carry a bivalent epigenetic signature, namely, repressive $\mathrm{H} 3 \mathrm{~K} 27 \mathrm{me} 3$ and activating H3K4me3 marks, in order to keep these genes quiet but to enable quick activation once a path of differentiation has been taken [68]. Upon initiation of differentiation bivalent chromatin structures are resolved and poised genes are either activated by removing repressive $\mathrm{H} 3 \mathrm{~K} 27 \mathrm{me} 3$ marks or permanently silenced by loss of activating H3K4me3 marks and accumulation of repressive $\mathrm{H} 3 \mathrm{~K} 27 \mathrm{me} 3$ marks $[68,69]$. Bivalent chromatin is also found in human and murine HSC. Genome-wide high resolution mapping of histone modifications revealed an association of developmental genes with bivalent epigenetic signatures in HSC and precursor cells, and, upon lineage commitment and differentiation, these bivalent structures are also resolved $[65,70]$. Interestingly, genes that become activated upon resolution of bivalent epigenetic signatures and in the course of lineage commitment are additionally associated with $\mathrm{H} 3 \mathrm{~K} 4 \mathrm{mel}$ and $\mathrm{H} 3 \mathrm{~K} 9 \mathrm{mel}$ marks in gene regulatory regions and also bound by RNA Pol II. This indicates that the choice of resolution of bivalent signatures during differentiation is already predetermined in HSC or progenitor cells [65].

$\mathrm{H} 3 \mathrm{~K} 4$ methylation is established by the SET1 and mixed lineage leukemia (MLL) family of histone methyltransferases [71-73] and is removed by the lysine-specific demethylase 1 (LSD1) [74] and the Jumonji AT-rich interactive domain 1 (JARID1) family of histone demethylases [75] (for review see [76]). The writer of repressive H3K27 methylation marks is the histone methyltransferases enhancer of zeste homolog 2 (EZH2), a subunit of the polycomb repressor complex 2 (PCR2) [77, 78], and erasers of methylated H3K27 include histone demethylase UTX (also known as Kdm6a) and Jmjd3 (also known as Kdm6b) [79-81].

The polycomb repressor complexes have been well characterized in HSC and are generally recognized as key factors in lineage determination. PRC2 mediates gene repression through the enzymatic activity of its histone methyltransferase subunit EZH2, which catalyzes H3K27 methylation. Methylated $\mathrm{H} 3 \mathrm{~K} 27$ is a binding platform for PRC1, which, in turn, is involved in heterochromatin formation. Genetic ablation of BMI1, a component of the $\mathrm{PRC1}$, results in defective long-term self-renewal capacity of HSC and in severe postnatal pancytopenia $[82,83]$. Moreover, loss of BMI1 leads to accelerated lymphoid specification due to premature expression of Ebf1 and Pax5 lineage markers, which are marked with bivalent epigenetic modifications in wild-type HSC [84]. In contrast, genetic deletion of Ezh2, the catalytic subunit of the PRC2 complex, does not compromise HSC self-renewal and $\mathrm{H} 3 \mathrm{~K} 27$ methylation is retained, probably due to complementary activity of Ezh1 $[85,86]$. Interestingly, ectopic expression of Ezh2 causes a significant increase in HSC numbers and myeloid lineage cells in a knock-in mouse model [87].

Another enzyme that actively shapes a cell's epigenome and eventually a cell's fate is the lysine-specific demethylase 1 (LSD1). LSD1 specifically removes one or two methyl groups from histone $\mathrm{H} 3$ lysine $4(\mathrm{H} 3 \mathrm{~K} 4)$ or 9 (H3K9), depending on the cellular context and the presence of cofactors, thereby repressing or activating transcription $[74,88]$. The complete LSD1 knockout results in embryonic preimplantation lethality and embryonic stem cells lacking LSD1 activity fail to differentiate fully [89-91]. Conditional ablation of the lysinespecific histone demethylase LSD1 in murine hematopoietic stem cells results in an aberrant accumulation of LSD1 substrates, namely, activating $\mathrm{H} 3 \mathrm{~K} 4 \mathrm{mel}$ and $\mathrm{H} 3 \mathrm{~K} 4 \mathrm{me} 2$ marks, at enhancers and promotors of stem- and progenitor cellspecific genes in differentiating cells. Failure to repress early lineage gene expression impairs hematopoietic maturation programs and eventually results in profound multilineage hematopoietic differentiation defects. This conversely means that, upon differentiation, LSD1 removes activating $\mathrm{H} 3 \mathrm{~K} 4$ methylation marks (H3K4me1, H3K4me2) from enhancer and promoter regions in order to silence hematopoietic stem and progenitor cell-specific genes and to promote differentiation [92].

5.2. DNA Methylation. Context- and tissue-specific gene expression is influenced by DNA methylation. The DNA methyltransferases DNMT3a and DNMT3b are responsible for de novo methylation of $\mathrm{CpG}$ dinucleotides whereas DNMT1 preserve DNA methylation patterns after DNA replication [93-95]. There is a remarkable plasticity in DNA methylation signatures during hematopoiesis pointing towards an essential role of methylation changes in cell fate and lineage commitment. Ji and colleagues analyzed differential methylation patterns in purified cell populations, hierarchically progressing in development and with wellcharacterized differentiation potentials. They developed a comprehensive map that indicates an orchestrated modulation of the DNA methylome during myeloid and lymphoid commitment from haematopoietic progenitors and that DNA methylation signatures specifically vary depending on the branch of differentiation, either myelopoiesis or lymphopoiesis, progenitors choose [96]. In principle, genes, involved in maintaining a more undifferentiated state, were progressively methylated and transcriptionally silenced in stem cells or progenitors as development proceeded. The transcription factors Meis1, Hoxa9, and Prdm16 were among these candidates [96-99]. On the other hand, genes that 
are initially transcriptionally inactive and found methylated in HSC or progenitors experience a selective demethylation during lineage commitment. For example, myeloid specification from MPP (multipotent progenitor) through GMP (granulocyte macrophage progenitor) cells was accompanied by transcriptional upregulation and progressive hypomethylation of Mpo, which encodes an enzyme central to the microbicidal activity of neutrophils $[100,101]$. Moreover, Gadd $45 a$, which is implicated in myeloid development, was found to be concomitantly upregulated and demethylated in the CMP to GMP transition [96]. The underlying mechanisms of (a) gene-specific DNA de novo methylation and (b) selective DNA demethylation in hematopoiesis, for example, passive dilution of $5 \mathrm{mC}$ in absence of DNMTs or active removal of modified $5 \mathrm{mC}$ via base excision repair (BER) mechanisms [102], are not well understood so far.

Conditional knockout mouse models try to explain the role of DNA methylation in maintenance of the HSC pool versus lineage commitment. HSC-specific deletion of the maintenance DNA methyltransferase revealed an essential function for DNMT1 in HSC self-renewal, niche retention, and proper differentiation of the myeloid lineage. DNMT1 seems to be critical for HSC and progenitor cell state transitions, such as the stepwise differentiation of HSC to ST-HSC/MPPs and ST-HSC/MPPs to myeloid progenitor [103]. Conditional inactivation of one or both de novo DNA methyltransferases DNMT3a and DNMT3b in HSC underlined the importance of gene-specific de novo methylation in regulation of HSC fate decisions [104, 105]. Loss of Dnmnt3 progressively impairs HSC differentiation over serial transplantation, while, at the same time, HSC numbers in the bone marrow increase. Methylome analyses of differentiating HSC descendants revealed a reduction in global as well as a loci-specific DNA methylation and consequently an increase in HSC multipotency genes, for example, Runxl and Gata3. In conclusion, DNMT3 plays a key role in HSC fate by repressing the HSC program and triggering lineage commitment. DNMT3 presumably silences HSCspecific genes by de novo DNA methylation and thus enables differentiation [104]. Combined loss of Dnmt3a and Dnmt3b was synergistic, resulting in enhanced HSC self-renewal and a more severe block in differentiation than in Dnmt3a-null cells, whereas loss of Dnmt $3 b$ resulted in a mild phenotype [105]. Epigenetic regulation of lineage-specific genes is a signature of HSC differentiation and lineage commitment (Figure 2).

Due to different requirements of HSC at different developmental stages, HSC show a difference in cell cycle activity. During fetal life HSC produce homeostatic levels of blood cells, mainly erythroid cells, to supply the fast growing organism with sufficient oxygen. In line with this, almost $100 \%$ of all fetal HSC are constantly cycling $[106,107]$. During late stages of fetal development and the first 2-3 weeks of neonatal life HSC migrate to their bone marrow niche and adult HSC are considered to be quiescent. This does not happen immediately after seeding the niche, but at 4 weeks of age $95 \%$ of HSC are quiescent. How this is achieved is not fully understood, yet. By this time, the development of the bone marrow niche is completed and perhaps feedback mechanisms of blood cells that have reached homeostasis are established $[106,108,109]$.

\section{Cell Cycle Regulation in Hematopoietic Stem Cells}

One key mechanism to maintain quiescence under homeostatic conditions in HSC is the control of cell cycle regulators (for review see [110]). Cyclins and Cyclin-dependent kinases (Cdks) regulate cell cycle progression. Cdks are serine-threonine kinases and after binding cyclins Cdks are recruited to their target proteins that regulate them through phosphorylation. Cyclin D1, cyclin D2, and cyclin D3 are expressed at different levels in HSC [111]. Quiescent HSC are in $\mathrm{G}_{0}$. To enter the cell cycle HSC have to activate the cyclin $\mathrm{D} / \mathrm{Cdk} 4 / 6$ complex that ensures entry into $\mathrm{G}_{1}$ by repression of the Retinoblastoma (RB) protein via phosphorylation. Inactivation of $\mathrm{RB}$ leads to the entry of S-phase by the activation of E2F transcription factors. Whether or not HSC enter the cell cycle is controlled by external signals like growth factors provided by the niche. If cells pass the "restriction point" between early and late G1 phase, they are determined to pass through the whole cell cycle. This makes G1/S transition very critical to regulate HSC quiescence. Inactivation of one of these factors has only a small effect on stem cell function pointing to a redundant role during cell cycle regulation $[112,113]$. Nevertheless, D1/2/3-cyclins ${ }^{-/-}$ mice and Cdk $4 / 6^{-/-}$mice have a decreased number of HSC in the fetal liver and reduced proliferation in erythroid cells $[113,114]$.

A recent study showed that CDK6 levels are essential for cells leaving $G_{0}$ and that HSC in the absence of CDK6 cannot respond to mitogenic signals $[115,116]$. Interestingly, quiescent LT-HSC and ST-HSC show different levels of CDK6. Quiescent LT-HSC do not express CDK6 and this delays cell cycle entry by 5-6 hours. In contrast, ST-LSK express moderate levels of CDK6 to keep them in a quiescent state and to allow them to enter the cell cycle upon mitogenic stress [115]. This delayed $\mathrm{G}_{0}$ exit might also be an important mechanism to coordinate DNA-repair of LT-HSC (see DNA damage response in HSC).

Negative cell cycle regulators interact with Cdks and lead to a cell cycle arrest and this makes CDK potent candidates to sustain stem cell quiescence by preventing cell cycle entry. They can be subdivided into INK4-family members (p15, p16, p18, and p19) binding to Cdk4/Cdk6 and Cip/Kip-family members (p21, p27, and p57) binding Cdk4/Cdk6 and Cdk2.

The negative cell cycle regulator $\mathrm{p} 57^{\mathrm{Kip} 1}$ is highly expressed in quiescent hematopoietic stem cells and declines with ongoing differentiation [111, 117]. Conditional inactivation of p57 using an inducible $\mathrm{Mx}$-Cre line (active in all hematopoietic cells) leads to a decrease of quiescent HSC and a perturbed capacity to reconstitute irradiated syngeneic mice [118]. Following a different approach, Zou and coworkers used fetal liver (FL) cells for transplantation experiments, because $\mathrm{p} 57^{-/-}$mice are neonatal lethal, to investigate the role of $\mathrm{p} 57^{\mathrm{Kipl}}$. They observed a normal reconstitution of the hematopoietic system after the first and 


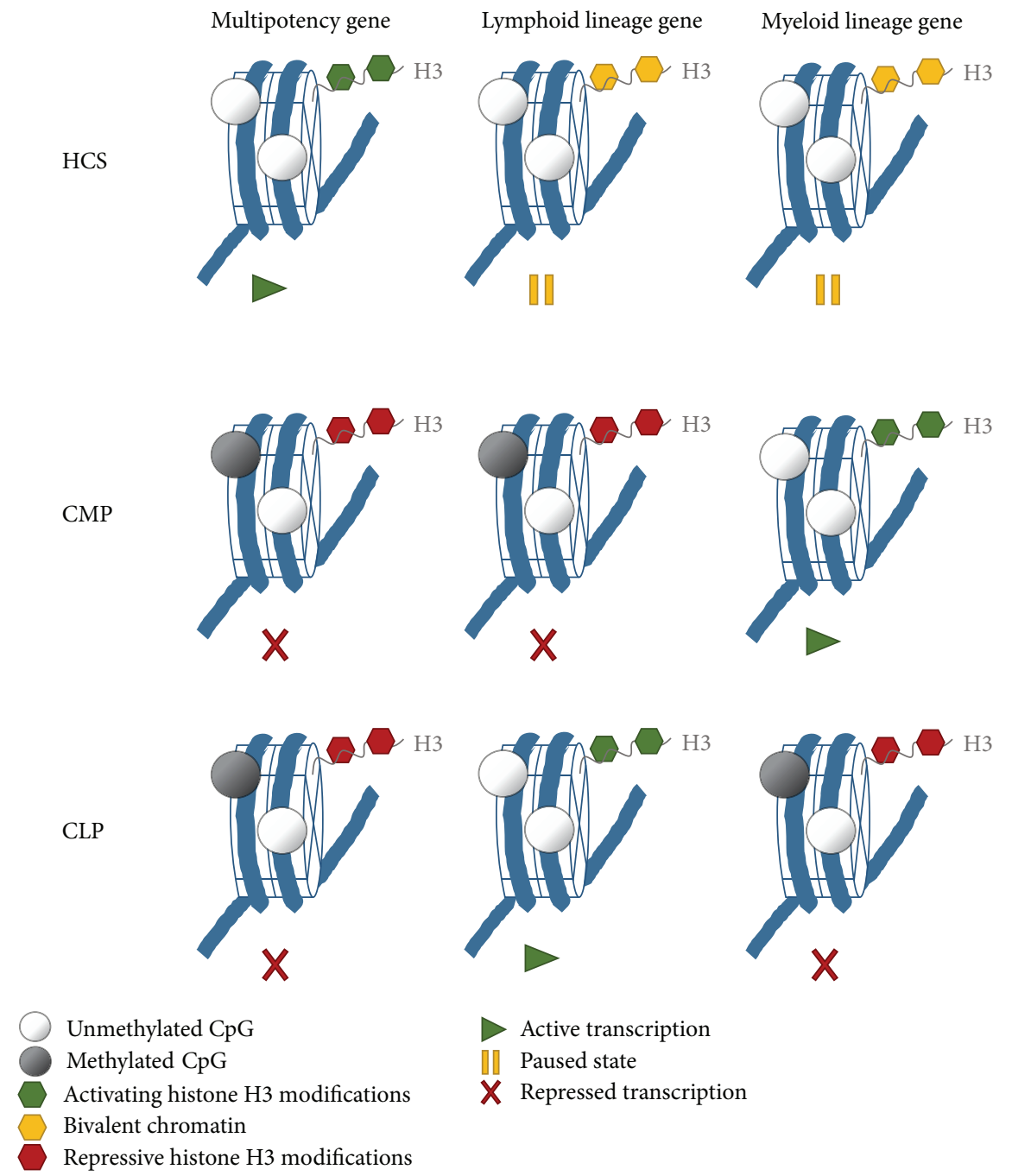

FIGURE 2: Changes in epigenetic signatures upon HSC differentiation and lineage commitment. Multipotency genes are actively transcribed in hematopoietic stem cells (HSC) to maintain stemness and self-renewal. Promoter and enhancer regions are labelled with activating H3K4 methylation marks (green hexagons) and unmethylated CpG islands (white circles). Key genes, important for lineage commitment and differentiation into progenitor cells of the myeloid (common myeloid progenitors (CMP)) or lymphoid lineage (common lymphoid progenitors (CLP)), are kept in a paused state mainly by the counteracting histone methylation marks H3K27me3 (repressive) and H3K4me3 (activating) in gene regulatory regions, termed as bivalent signatures (yellow hexagons). Upon lineage commitment, multipotency genes are silenced by repressive histone methylation marks (e.g., $\mathrm{H} 3 \mathrm{~K} 27 \mathrm{~m} 3, \mathrm{H} 3 \mathrm{~K} 9 \mathrm{me}$, and red hexagons) and partially by gene-specific de novo methylation of $\mathrm{CpG}$ islands (grey circles). Upon differentiation bivalent chromatin signatures are resolved depending on lineage choice: paused genes become either activated transcriptionally by accumulation of activating H3K4me3 marks and loss of repressive H3K27me3 or silenced by loss of $\mathrm{H} 3 \mathrm{~K} 4 \mathrm{me} 3$ and accumulation of $\mathrm{H} 3 \mathrm{~K} 27 \mathrm{me} 3$ and partially by gene-specific methylation of $\mathrm{CpG}$ islands.

second round of transplantation and only a mild decrease after the third round of transplantation [119]. The authors noticed a significant compensatory upregulation of p18 and p27 in $\mathrm{p} 57^{-/-}$FL HSC. Inactivation of $\mathrm{p} 27$ in $\mathrm{p} 57^{-/-} \mathrm{FL}$ HSC leads to a reduced reconstitution capacity after serial transplantation and decreased HSC quiescence. This indicatesthat the compensatory upregulation of p27 in p53-deficient FL HSC preserves HSC functionality and quiescence. In addition, inhibition of p27 alone does not affect the number of self-renewing HSC but however increases the size of the haematopoietic progenitor pool [120]. Taken together, these findings show that p27 can compensate for the loss of p57 but also points to distinct role of some Cdk inhibitors during hematopoietic development under normal conditions.
The negative cell cycle regulator $\mathrm{p} 21^{\mathrm{Cip}}$ is highly expressed in HSC and a role in regulating quiescence had been sug-

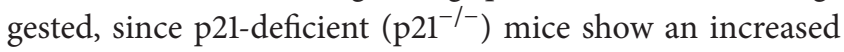
proliferation and a higher number of HSC [121]. However, recent reports point to a role of $\mathrm{p} 21^{\mathrm{Cip}}$ in regulating cell cycle activity during stress response rather than during homeostasis $[4,52]$. This finding was further supported by p57 and p21 deficient HSC. These mutants resembled p57 deficient HSC and only showed a severe reduction in colony-forming capacity, suggesting again an important role of p21 during stress response rather than during homeostasis [118].

It has recently been shown that also the members of the INK4-family play a critical role in HSC functions. p16 ${ }^{\text {INK4a }}$ expression is repressed by EZH1 in young mice [122] but 
increases with age [123]. This leads to a decreased selfrenewal, homing, and repopulating of HSC in response to stress [123]. Nevertheless, maintaining steady-state HSC aging in vivo appears to be independent of $\mathrm{p} 16^{\mathrm{INK} 4 \mathrm{a}}$ [124]. Mice missing the negative cell cycle regulator $\mathrm{p} 19^{\mathrm{INK} 4 \mathrm{~d}}$ show a reduced number of $\mathrm{HSC}$ and an increased $\mathrm{G}_{0} / \mathrm{G}_{1}$ transition [125]. Furthermore, p19 ${ }^{\mathrm{INK} 4 \mathrm{~d}}$ deficient HSC showed a decreased transition through S/G2-M phase and an increase in apoptosis [125].

\section{DNA Damage Response in HSC}

During their entire life hematopoietic stem cells are mainly quiescent and this is considered as a protective mechanism to minimize cell intrinsic stress [126]. Mice lacking proper DNA damage repair (DDR) mechanisms show severe hematopoietic phenotypes caused by malfunctioning $\operatorname{HSC}[3,127,128]$. In particular, HSC accumulate DNA damage during aging, which is responsible for the development of cancer in elderly people [3]. Defects in DDR have also been associated with a wide range of human blood diseases [129]. It has previously been shown that HSC are more radioresistant than faster cycling progenitor cells $[130,131]$. This is consistent with intracellular levels of reactive oxygen species (ROS) in HSC and developing progenitors [132]. Quiescent HSC showed a reduced intracellular ROS concentration compared to other progenitor cells [132]. Interestingly, ROS levels of HSC are regulated by Forkhead transcription factors. FoxO1, FoxO3, and FoxO4 deficient mice showed elevated ROS levels in HSC, whereas ROS levels in myeloid cells were not altered, indicating that FOXO-proteins act specifically in quiescent HSC to maintain their functionality [132].

Hematopoietic stem and progenitor cells (HSPC) from young are more resistant to radiation than downstream myeloid progenitor cells [8]. This radiation resistance is mediated through "ataxia telangiectasia mutated" (ATM) because in the absence of ATM all populations are equally sensitive to radiation. The authors could further show that quiescent HSC induce cell cycle arrest, the expression of prosurvival factors, and the activation of concurrent DNA repair. Upon stress, HSC also induce a strong p53 response and an upregulation of proapoptotic genes (i.e., bax, nova, and puma) and Cdknla (p21) expression. In contrast, myeloid progenitors are mainly eliminated by apoptosis [8]. HSC preferentially show nonhomologous end joining- (NHEJ-) mediated DNA repair that renders quiescent HSC susceptible to genomic instability, which can contribute to HSC loss of function and malignant transformation. In contrast, proliferating HSC undergo DNA repair using homologous recombination (HR) mechanism and show a decreased risk of acquiring mutation (Figure 3) [8].

Interestingly, a recent study demonstrated a unique but different mechanism of how human HSC respond to DNA damage. Here, DNA damage is regulated by a strong induction of p53-induced apoptosis [133]. p53-induced apoptosis in human umbilical cord blood HSC can be inhibited by blocking $\mathrm{p} 53$ expression or ectopic expression of the antiapoptotic factor Bcl-2. Interestingly, Milyavsky and coworkers also

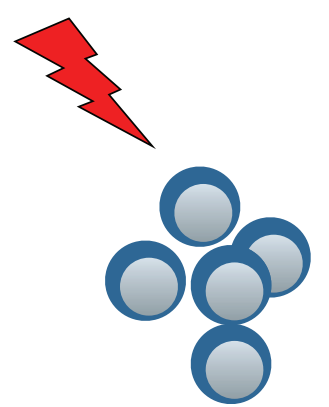

Quiescent HSC

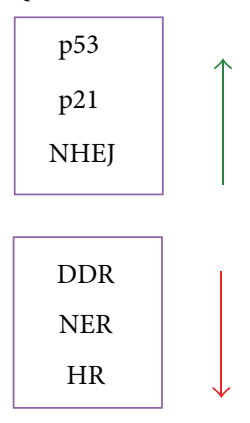

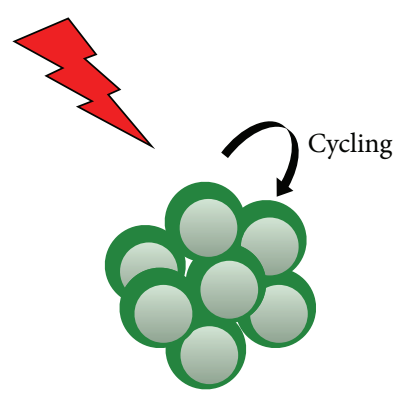

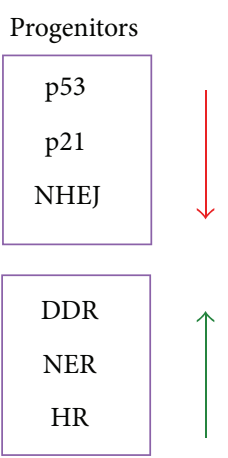

FIGURE 3: Quiescent HSC and proliferating progenitors respond differently to DNA damage (radiation). HSC show a higher expression level of p53 and p 21 and they activate the error-prone repair pathway compared to faster cycling progenitors. They show a reduced DDR, NER, and HR response. (NHEJ: nonhomologous end joining; DDR: DNA damage response; NER: nucleotide excision repair; and HR: homologous recombination).

showed that p53 fulfills an apoptosis-independent role in the regulation of self-renewal capacity of HSC [133]. To investigate the role of p53 in long-term repopulation the authors performed serial transplantation assays and could show that inactivation of $\mathrm{p} 53$ leads to an accumulation of DNA damage and a decreased self-renewal capacity compared to Bcl-2 overexpressing cells. This clearly points to an apoptosis independent function of p53 in long-term repopulation experiments. Why murine HSC respond with DNA repair and do not undergo apoptosis is not fully understood yet. However, there are also some technical differences in these two studies. First of all, umbilical cord blood HSC are not equivalent to quiescent murine HSC. In addition, transplantation efficiency of human HSC in mouse bone marrow niches might not provide the same homing capacity and a decreased survival rate.

Mohrin and colleagues postulated that also high levels of prosurvival factors counteract the proapoptotic signals. Furthermore, the transcription factor Myc interacting zinc finger protein 1 (Miz-1) has been shown to be the "Miz-ing" link in switching from life to death $[134,135]$. Miz-1 regulates Bcl-2 expression and Miz-1 deficient mice showed a high degree of apoptosis in the hematopoietic system [136, 137]. p53 is highly expressed in murine HSC and regulates HSC quiescence and self-renewal and this is critical for preserving the lifelong HSC pool [138]. p53-deficient mice show an increased percentage of HSC, with a reduced potential of long-term repopulation $[138,139]$. Furthermore, p53 reduces 
also the level of ROS under physiological conditions. The high level of p53 in quiescent HSC protects stem cells from DNA damage and accumulation of mutations [140].

Aging of the hematopoietic system is associated with several changes like reduced lymphocyte counts and antibody diversity, autoimmunity, altered regeneration potential, and finally diseases like leukemia [141-143]. It has been shown that the HSC pool changes and lymphoid primed HSC decline with age, while myeloid primed HSC increase [144]. However, also myeloid progenitors lose their functionality [145]. Furthermore, the decreased potential of aged HSC might be caused by an age-associated accumulation of DNA damage $[3,142,146]$ or it might be also linked to telomere shortening $[147,148]$. Very recent findings show that replicative stress leads to DNA damage in old HSC. In addition, persistent damage was connected to a reduced expression of rDNA genes. This leads to fewer ribosomes and subsequently a reduced protein synthesis [149].

These findings point to a specific mechanism in quiescent HSC to protect them against DNA damage. Thus, there is a necessity that quiescent HSC have to be protected against DNA damage during aging to maintain functionality. Otherwise, they would either lose their stem cell potential or acquire mutations that might lead to severe hematopoietic disorders.

However, recent findings demonstrate an attenuation of DNA damage responses during aging that leads to an accumulation of damaged DNA in quiescent $\operatorname{HSC}[3,150]$. Aging HSC acquire DNA damage over time, and if these cells are activated by stress signals, they show a severely reduced functional capacity. This explains why aged HSC lose their potential to generate different hematopoietic lineages $[141,151]$. Furthermore, a recent study also showed that DNA damage is a direct consequence of HSC to leaving their homeostatic quiescence in response to physiological stress, like infections or anemia [152].

Interestingly, recent work shows that repair mechanisms are activated upon entering cell cycle [153]. Beerman and colleagues could show that quiescent HSCs and progenitor cells acquire similar amounts of DNA damage but attenuation of the DNA repair and response pathways lead to an accumulation of damaged DNA in HSC over time. Cell cycle entry of these HSC leads to the activation of multiple DNA damage response pathways and the repair of accumulated DNA damage [153]. Together with the finding that activated HSC can return into quiescence this might be a possibility of how DNA damage repair mechanisms can maintain the stem cell pool, at least for some HSC [5].

\section{Conclusion}

In this review, we discussed several factors that contribute to the functionality of the hematopoietic stem cell compartment, with special regard to maintenance of stemness versus lineage commitment and differentiation. Several transcription factors, epigenetic modifiers, and cytokine and chemokine signals are crucial to balance cell fate in hematopoiesis. During aging, these mechanisms might lose effectiveness, since the HSC pool shows a reduced capacity in replenishing the hematopoietic system with mature cells and an altered lineage potential $[142,154,155]$. Understanding these molecular mechanisms is of tremendous importance, not only to obtain new insight into developmentally related cell fate decisions but also to gain knowledge about the origin of hematopoietic diseases like cancer, anemia, or autoimmunity. Moreover, this knowledge might eventually also contribute to improvement of the efficiency in adaptive transfer of HSC in immunodeficient patients or after radiation therapy.

\section{Conflict of Interests}

The authors declare that there is no conflict of interests regarding the publication of this paper.

\section{References}

[1] S. Doulatov, F. Notta, E. Laurenti, and J. E. Dick, "Hematopoiesis: a human perspective," Cell Stem Cell, vol. 10, no. 2, pp. 120136, 2012.

[2] A. Wilson, E. Laurenti, and A. Trumpp, "Balancing dormant and self-renewing hematopoietic stem cells," Current Opinion in Genetics and Development, vol. 19, no. 5, pp. 461-468, 2009.

[3] D. J. Rossi, J. Seita, A. Czechowicz, D. Bhattacharya, D. Bryder, and I. L. Weissman, "Hematopoietic stem cell quiescence attenuates DNA damage response and permits DNA damage accumulation during aging," Cell Cycle, vol. 6, no. 19, pp. 23712376, 2007.

[4] A. Foudi, K. Hochedlinger, D. Van Buren et al., "Analysis of histone 2B-GFP retention reveals slowly cycling hematopoietic stem cells," Nature Biotechnology, vol. 27, no. 1, pp. 84-90, 2009.

[5] A. Wilson, E. Laurenti, G. Oser et al., "Hematopoietic stem cells reversibly switch from dormancy to self-renewal during homeostasis and repair," Cell, vol. 135, no. 6, pp. 1118-1129, 2008.

[6] H. Takizawa, R. R. Regoes, C. S. Boddupalli, S. Bonhoeffer, and M. G. Manz, "Dynamic variation in cycling of hematopoietic stem cells in steady state and inflammation," The Journal of Experimental Medicine, vol. 208, no. 2, pp. 273-284, 2011.

[7] J. Seita and I. L. Weissman, "Hematopoietic stem cell: selfrenewal versus differentiation," Wiley Interdisciplinary Reviews: Systems Biology and Medicine, vol. 2, no. 6, pp. 640-653, 2010.

[8] M. Mohrin, E. Bourke, D. Alexander et al., "Hematopoietic stem cell quiescence promotes error-prone DNA repair and mutagenesis," Cell Stem Cell, vol. 7, no. 2, pp. 174-185, 2010.

[9] A. Trumpp, M. Essers, and A. Wilson, "Awakening dormant haematopoietic stem cells," Nature Reviews Immunology, vol. 10, no. 3, pp. 201-209, 2010.

[10] S. J. Morrison and I. L. Weissman, "The long-term repopulating subset of hematopoietic stem cells is deterministic and isolatable by phenotype," Immunity, vol. 1, no. 8, pp. 661-673, 1994.

[11] J. Adolfsson, R. Månsson, N. Buza-Vidas et al., "Identification of $\mathrm{Flt}^{+}$lympho-myeloid stem cells lacking erythromegakaryocytic potential: a revised road map for adult blood lineage commitment," Cell, vol. 121, no. 2, pp. 295-306, 2005.

[12] K. Akashi, D. Traver, T. Miyamoto, and I. L. Weissman, "A clonogenic common myeloid progenitor that gives rise to all myeloid lineages," Nature, vol. 404, no. 6774, pp. 193-197, 2000.

[13] J. L. Christensen and I. L. Weissman, "Flk-2 is a marker in hematopoietic stem cell differentiation: a simple method 
to isolate long-term stem cells," Proceedings of the National Academy of Sciences of the United States of America, vol. 98, no. 25, pp. 14541-14546, 2001.

[14] M. Kondo, I. L. Weissman, and K. Akashi, "Identification of clonogenic common lymphoid progenitors in mouse bone marrow," Cell, vol. 91, no. 5, pp. 661-672, 1997.

[15] C. J. H. Pronk, D. J. Rossi, R. Månsson et al., "Elucidation of the phenotypic, functional, and molecular topography of a myeloerythroid progenitor cell hierarchy," Cell Stem Cell, vol. 1, no. 4, pp. 428-442, 2007.

[16] J. N. P. Smith and L. M. Calvi, "Concise review: current concepts in bone marrow microenvironmental regulation of hematopoietic stem and progenitor cells," STEM CELLS, vol. 31, no. 6, pp. 1044-1050, 2013.

[17] T. Suda, K. Takubo, and G. L. Semenza, "Metabolic regulation of hematopoietic stem cells in the hypoxic niche," Cell Stem Cell, vol. 9, no. 4, pp. 298-310, 2011.

[18] A. Wilson and A. Trumpp, "Bone-marrow haematopoieticstem-cell niches," Nature Reviews Immunology, vol. 6, no. 2, pp. 93-106, 2006.

[19] A. Mendelson and P. S. Frenette, "Hematopoietic stem cell niche maintenance during homeostasis and regeneration," Nature Medicine, vol. 20, no. 8, pp. 833-846, 2014.

[20] S. J. Morrison and D. T. Scadden, "The bone marrow niche for haematopoietic stem cells," Nature, vol. 505, no. 7483, pp. 327334, 2014.

[21] A. Greenbaum, Y.-M. S. Hsu, R. B. Day et al., "CXCL12 in early mesenchymal progenitors is required for haematopoietic stemcell maintenance," Nature, vol. 495, no. 7440, pp. 227-230, 2013.

[22] T. Sugiyama, H. Kohara, M. Noda, and T. Nagasawa, "Maintenance of the hematopoietic stem cell pool by CXCL12-CXCR4 chemokine signaling in bone marrow stromal cell niches," Immunity, vol. 25, no. 6, pp. 977-988, 2006.

[23] H. E. Fleming, V. Janzen, C. Lo Celso et al., "Wnt signaling in the niche enforces hematopoietic stem cell quiescence and is necessary to preserve self-renewal in vivo," Cell Stem Cell, vol. 2, no. 3, pp. 274-283, 2008.

[24] G. Jeannet, M. Scheller, L. Scarpellino et al., "Long-term, multilineage hematopoiesis occurs in the combined absence of beta-catenin and gamma-catenin," Blood, vol. 111, no. 1, pp. 142149, 2008.

[25] U. Koch, A. Wilson, M. Cobas, R. Kemler, H. R. MacDonald, and F. Radtke, "Simultaneous loss of beta- and gamma-catenin does not perturb hematopoiesis or lymphopoiesis," Blood, vol. 111, no. 1, pp. 160-164, 2008.

[26] S. Babovic and C. J. Eaves, "Hierarchical organization of fetal and adult hematopoietic stem cells," Experimental Cell Research, vol. 329, no. 2, pp. 185-191, 2014.

[27] L. Rossi, K. K. Lin, N. C. Boles et al., "Less is more: unveiling the functional core of hematopoietic stem cells through knockout mice," Cell Stem Cell, vol. 11, no. 3, pp. 302-317, 2012.

[28] L. Robb, I. Lyons, R. Li et al., "Absence of yolk sac hematopoiesis from mice with a targeted disruption of the scl gene," Proceedings of the National Academy of Sciences of the United States of America, vol. 92, no. 15, pp. 7075-7079, 1995.

[29] R. A. Shivdasanl, E. L. Mayer, and S. H. Orkin, "Absence of blood formation in mice lacking the T-cell leukaemia oncoprotein tal1/SCL," Nature, vol. 373, no. 6513, pp. 432-434, 1995.

[30] M. A. Hall, D. J. Curtis, D. Metcalf et al., "The critical regulator of embryonic hematopoiesis, SCL, is vital in the adult for megakaryopoiesis, erythropoiesis, and lineage choice in CFUS12," Proceedings of the National Academy of Sciences of the United States of America, vol. 100, no. 3, pp. 992-997, 2003.

[31] L. Robb and C. G. Begley, "The SCL/TAL1 gene: roles in normal and malignant haematopoiesis," BioEssays, vol.19, no. 7, pp. 607613, 1997.

[32] H. K. A. Mikkola, J. Klintman, H. Yang et al., "Haematopoietic stem cells retain long-term repopulating activity and multipotency in the absence of stem-cell leukaemia SCL/tal-1 gene," Nature, vol. 421, no. 6922, pp. 547-551, 2003.

[33] T. M. Schlaeger, H. K. A. Mikkola, C. Gekas, H. B. Helgadottir, and S. H. Orkin, "Tie2Cre-mediated gene ablation defines the stem-cell leukemia gene (SCL/tal1)-dependent window during hematopoietic stem-cell development," Blood, vol. 105, no. 10, pp. 3871-3874, 2005.

[34] J. Lacombe, S. Herblot, S. Rojas-Sutterlin et al., "Scl regulates the quiescence and the long-term competence of hematopoietic stem cells," Blood, vol. 115, no. 4, pp. 792-803, 2010.

[35] P. E. Mead, A. E. Deconinck, T. L. Huber, S. H. Orkin, and L. I. Zon, "Primitive erythropoiesis in the Xenopus embryo: the synergistic role of LMO-2, SCL and GATA-binding proteins," Development, vol. 128, no. 12, pp. 2301-2308, 2001.

[36] H. Osada, G. Grutz, H. Axelson, A. Forster, and T. H. Rabbitts, "Association of erythroid transcription factors: complexes involving the LIM protein RBTN2 and the zinc-finger protein GATA1," Proceedings of the National Academy of Sciences of the United States of America, vol. 92, no. 21, pp. 9585-9589, 1995.

[37] I. A. Wadman, H. Osada, G. G. Grütz et al., "The LIM-only protein Lmo2 is a bridging molecule assembling an erythroid, DNA-binding complex which includes the TAL1, E47, GATA-1 and Ldb1/NLI proteins," The EMBO Journal, vol. 16, no. 11, pp. 3145-3157, 1997.

[38] E. de Pater, P. Kaimakis, C. S. Vink et al., "Gata2 is required for HSC generation and survival," Journal of Experimental Medicine, vol. 210, no. 13, pp. 2843-2850, 2013.

[39] F.-Y. Tsal, G. Keller, F. C. Kuo et al., "An early haematopoietic defect in mice lacking the transcription factor GATA-2," Nature, vol. 371, no. 6494, pp. 221-226, 1994.

[40] F.-Y. Tsai and S. H. Orkin, "Transcription factor GATA-2 is required for proliferation/survival of early hematopoietic cells and mast cell formation, but not for erythroid and myeloid terminal differentiation," Blood, vol. 89, no. 10, pp. 3636-3643, 1997.

[41] B. van Riel, T. Pakozdi, R. Brouwer et al., "A novel complex, RUNX1-MYEF2, represses hematopoietic genes in erythroid cells," Molecular and Cellular Biology, vol. 32, no. 19, pp. 38143822, 2012.

[42] N. K. Wilson, S. D. Foster, X. Wang et al., "Combinatorial transcriptional control in blood stem/progenitor cells: genomewide analysis of ten major transcriptional regulators," Cell Stem Cell, vol. 7, no. 4, pp. 532-544, 2010.

[43] M. J. Chen, T. Yokomizo, B. M. Zeigler, E. Dzierzak, and N. A. Speck, "Runxl is required for the endothelial to haematopoietic cell transition but not thereafter," Nature, vol. 457, no. 7231, pp. 887-891, 2009.

[44] Y. Fujiwara, C. P. Browne, K. Cunniff, S. C. Goff, and S. H. Orkin, "Arrested development of embryonic red cell precursors in mouse embryos lacking transcription factor GATA-1," Proceedings of the National Academy of Sciences of the United States of America, vol. 93, no. 22, pp. 12355-12358, 1996. 
[45] H. Iwasaki, S.-I. Mizuno, R. A. Wells, A. B. Cantor, S. Watanabe, and K. Akashi, "GATA-1 converts lymphoid and myelomonocytic progenitors into the megakaryocyte/erythrocyte lineages," Immunity, vol. 19, no. 3, pp. 451-462, 2003.

[46] E. Igwe, C. Kosan, C. Khandanpour, E. Sharif-Askari, B. Brüne, and T. Möröy, "The zinc finger protein Gfil is implicated in the regulation of IgG2b production and the expression of Igamma2b germline transcripts," European Journal of Immunology, vol. 38, no. 11, pp. 3004-3014, 2008.

[47] H. Karsunky, I. Mende, T. Schmidt, and T. Möröy, "High levels of the onco-protein Gfi-1 accelerate T-cell proliferation and inhibit activation induced T-cell death in Jurkat T-cells," Oncogene, vol. 21, no. 10, pp. 1571-1579, 2002.

[48] C. Khandanpour, E. Sharif-Askari, L. Vassen et al., "Evidence that growth factor independence $1 \mathrm{~b}$ regulates dormancy and peripheral blood mobilization of hematopoietic stem cells," Blood, vol. 116, no. 24, pp. 5149-5161, 2010.

[49] D. Pargmann, R. Yücel, C. Kosan et al., "Differential impact of the transcriptional repressor Gfil on mature $\mathrm{CD} 4^{+}$and $\mathrm{CD}^{+} \mathrm{T}$ lymphocyte function," European Journal of Immunology, vol. 37, no. 12, pp. 3551-3563, 2007.

[50] H. Zeng, R. Yücel, C. Kosan, L. Klein-Hitpass, and T. Möröy, "Transcription factor Gfil regulates self-renewal and engraftment of hematopoietic stem cells," The EMBO Journal, vol. 23, no. 20, pp. 4116-4125, 2004.

[51] H. Hock, M. J. Hamblen, H. M. Rooke et al., "Gfi-1 restricts proliferation and preserves functional integrity of haematopoietic stem cells," Nature, vol. 431, no. 7011, pp. 1002-1007, 2004.

[52] R. Van Os, L. M. Kamminga, A. Ausema et al., "A limited role for p21Cip1/Waf1 in maintaining normal hematopoietic stem cell functioning," Stem Cells, vol. 25, no. 4, pp. 836-843, 2007.

[53] C. Khandanpour, C. Kosan, M.-C. Gaudreau et al., "Growth factor independence 1 protects hematopoietic stem cells against apoptosis but also prevents the development of a myeloproliferative-like disease," Stem Cells, vol. 29, no. 2, pp. 376-385, 2011.

[54] A. Foudi, D. J. Kramer, J. Qin et al., "Distinct, strict requirements for Gfi-lb in adult bone marrow red cell and platelet generation," The Journal of Experimental Medicine, vol. 211, no. 5, pp. 909927, 2014.

[55] S. Saleque, S. Cameron, and S. H. Orkin, "The zinc-finger protooncogene Gfi-lb is essential for development of the erythroid and megakaryocytic lineages," Genes \& Development, vol. 16, no. 3, pp. 301-306, 2002.

[56] E. Laurenti, B. Varnum-Finney, A. Wilson et al., "Hematopoietic stem cell function and survival depend on c-Myc and N-Myc activity," Cell Stem Cell, vol. 3, no. 6, pp. 611-624, 2008.

[57] A. C. Wilkinson and B. Göttgens, "Transcriptional regulation of haematopoietic stem cells," in Transcriptional and Translational Regulation of Stem Cells, vol. 786 of Advances in Experimental Medicine and Biology, pp. 187-212, Springer, Dordrecht, The Netherlands, 2013.

[58] S. Saleque, J. Kim, H. M. Rooke, and S. H. Orkin, "Epigenetic regulation of hematopoietic differentiation by Gfi-1 and Gfi-1b is mediated by the cofactors CoREST and LSD1," Molecular Cell, vol. 27 , no. 4 , pp. 562-572, 2007.

[59] F. Heyd, R. Chen, K. Afshar et al., "The p150 subunit of the histone chaperone Caf-1 interacts with the transcriptional repressor Gfil," Biochimica et Biophysica Acta, vol. 1809, no. 46, pp. 255-261, 2011.

[60] B. Laurent, V. Randrianarison-Huetz, Z. Kadri, P.-H. Roméo, F. Porteu, and D. Duménil, "Gfi-1B promoter remains associated with active chromatin marks throughout erythroid differentiation of human primary progenitor cells," Stem Cells, vol. 27, no. 9, pp. 2153-2162, 2009.

[61] D. E. Montoya-Durango, C. S. Velu, A. Kazanjian et al., "Ajuba functions as a histone deacetylase-dependent co-repressor for autoregulation of the growth factor-independent-1 transcription factor," The Journal of Biological Chemistry, vol. 283, no. 46, pp. 32056-32065, 2008.

[62] T. Kouzarides, "Chromatin modifications and their function," Cell, vol. 128, no. 4, pp. 693-705, 2007.

[63] M. Tan, H. Luo, S. Lee et al., "Identification of 67 histone marks and histone lysine crotonylation as a new type of histone modification," Cell, vol. 146, no. 6, pp. 1016-1028, 2011.

[64] A. J. Bannister and T. Kouzarides, "Reversing histone methylation," Nature, vol. 436, no. 7054, pp. 1103-1106, 2005.

[65] K. Cui, C. Zang, T.-Y. Roh et al., "Chromatin signatures in multipotent human hematopoietic stem cells indicate the fate of bivalent genes during differentiation," Cell Stem Cell, vol. 4, no. 1, pp. 80-93, 2009.

[66] H. Jiang, A. Shukla, X. Wang, W.-Y. Chen, B. E. Bernstein, and R. G. Roeder, "Role for Dpy-30 in ES cell-fate specification by regulation of H3K4 methylation within bivalent domains," Cell, vol. 144, no. 4, pp. 513-525, 2011.

[67] X. Shen, Y. Liu, Y.-J. Hsu et al., "EZH1 mediates methylation on histone H3 lysine 27 and complements EZH2 in maintaining stem cell identity and executing pluripotency," Molecular Cell, vol. 32, no. 4, pp. 491-502, 2008.

[68] B. E. Bernstein, T. S. Mikkelsen, X. Xie et al., "A bivalent chromatin structure marks key developmental genes in embryonic stem cells," Cell, vol. 125, no. 2, pp. 315-326, 2006.

[69] T. S. Mikkelsen, M. Ku, D. B. Jaffe et al., "Genome-wide maps of chromatin state in pluripotent and lineage-committed cells," Nature, vol. 448, no. 7153, pp. 553-560, 2007.

[70] H. Weishaupt, M. Sigvardsson, and J. L. Attema, "Epigenetic chromatin states uniquely define the developmental plasticity of murine hematopoietic stem cells," Blood, vol. 115, no. 2, pp. 247-256, 2010.

[71] S. Denissov, H. Hofemeister, H. Marks et al., "Mll2 is required for $\mathrm{H} 3 \mathrm{~K} 4$ trimethylation on bivalent promoters in embryonic stem cells, whereas Mll1 is redundant," Development, vol. 141, no. 3, pp. 526-537, 2014.

[72] S. Glaser, J. Schaft, S. Lubitz et al., "Multiple epigenetic maintenance factors implicated by the loss of Mll2 in mouse development," Development, vol. 133, no. 8, pp. 1423-1432, 2006.

[73] T. A. Milne, S. D. Briggs, H. W. Brock et al., "MLL targets SET domain methyltransferase activity to Hox gene promoters," Molecular Cell, vol. 10, no. 5, pp. 1107-1117, 2002.

[74] Y. Shi, F. Lan, C. Matson et al., "Histone demethylation mediated by the nuclear amine oxidase homolog LSD1," Cell, vol. 119, no. 7, pp. 941-953, 2004.

[75] R. J. Klose, Q. Yan, Z. Tothova et al., "The retinoblastoma binding protein RBP2 is an H3K4 demethylase," Cell, vol. 128, no. 5, pp. 889-900, 2007.

[76] R. J. Klose and Y. Zhang, "Regulation of histone methylation by demethylimination and demethylation," Nature Reviews Molecular Cell Biology, vol. 8, no. 4, pp. 307-318, 2007.

[77] R. Cao, L. Wang, H. Wang et al., "Role of histone H3 lysine 27 methylation in polycomb-group silencing," Science, vol. 298, no. 5595, pp. 1039-1043, 2002.

[78] B. Czermin, R. Melfi, D. McCabe, V. Seitz, A. Imhof, and V. Pirrotta, "Drosophila enhancer of Zeste/ESC complexes have 
a histone $\mathrm{H} 3$ methyltransferase activity that marks chromosomal Polycomb sites," Cell, vol. 111, no. 2, pp. 185-196, 2002.

[79] S. Hong, Y.-W. Cho, L.-R. Yu, H. Yu, T. D. Veenstra, and K. Ge, "Identification of JmjC domain-containing UTX and JMJD3 as histone H3 lysine 27 demethylases," Proceedings of the National Academy of Sciences of the United States of America, vol. 104, no. 47, pp. 18439-18444, 2007.

[80] A. A. Mansour, O. Gafni, L. Weinberger et al., “The H3K27 demethylase Utx regulates somatic and germ cell epigenetic reprogramming," Nature, vol. 488, no. 7411, pp. 409-413, 2012.

[81] Y. Xiang, Z. Zhu, G. Han, H. Lin, L. Xu, and C. D. Chen, "JMJD3 is a histone H3K27 demethylase," Cell Research, vol. 17, no. 10, pp. 850-857, 2007.

[82] A. Iwama, H. Oguro, M. Negishi, Y. Kato, and H. Nakauchi, "Epigenetic regulation of hematopoietic stem cell self-renewal by polycomb group genes," International Journal of Hematology, vol. 81, no. 4, pp. 294-300, 2005.

[83] J. Lessard and G. Sauvageau, "Bmi-1 determines the proliferative capacity of normal and leukaemic stem cells," Nature, vol. 423, no. 6937, pp. 255-260, 2003.

[84] H. Oguro, J. Yuan, H. Ichikawa et al., "Poised lineage specification in multipotential hematopoietic stem and progenitor cells by the polycomb protein Bmil," Cell Stem Cell, vol. 6, no. 3, pp. 279-286, 2010.

[85] M. Mochizuki-Kashio, Y. Mishima, S. Miyagi et al., "Dependency on the polycomb gene Ezh2 distinguishes fetal from adult hematopoietic stem cells," Blood, vol. 118, no. 25, pp. 6553-6561, 2011.

[86] I.-H. Su, M.-W. Dobenecker, E. Dickinson et al., "Polycomb group protein Ezh2 controls actin polymerization and cell signaling," Cell, vol. 121, no. 3, pp. 425-436, 2005.

[87] A. Herrera-Merchan, L. Arranz, J. M. Ligos, A. De Molina, O. Dominguez, and S. Gonzalez, "Ectopic expression of the histone methyltransferase Ezh2 in haematopoietic stem cells causes myeloproliferative disease," Nature Communications, vol. 3, article 623, 2012.

[88] E. Metzger, M. Wissmann, N. Yin et al., "LSD1 demethylates repressive histone marks to promote androgen-receptordependent transcription," Nature, vol. 437, no. 7057, pp. 436439, 2005.

[89] J. Wang, S. Hevi, J. K. Kurash et al., "The lysine demethylase LSD1 (KDM1) is required for maintenance of global DNA methylation," Nature Genetics, vol. 41, no. 1, pp. 125-129, 2009.

[90] J. Wang, K. Scully, X. Zhu et al., "Opposing LSD1 complexes function in developmental gene activation and repression programmes," Nature, vol. 446, no. 7138, pp. 882-887, 2007.

[91] W. A. Whyte, S. Bilodeau, D. A. Orlando et al., "Enhancer decommissioning by LSD1 during embryonic stem cell differentiation," Nature, vol. 482, no. 7384, pp. 221-225, 2012.

[92] M. A. Kerenyi, Z. Shao, Y.-J. Hsu et al., "Histone demethylase Lsd1 represses hematopoietic stem and progenitor cell signatures during blood cell maturation," eLife, vol. 2, Article ID e00633, 2013.

[93] T. Chen, Y. Ueda, J. E. Dodge, Z. Wang, and E. Li, "Establishment and maintenance of genomic methylation patterns in mouse embryonic stem cells by Dnmt3a and Dnmt3b," Molecular and Cellular Biology, vol. 23, no. 16, pp. 5594-5605, 2003.

[94] T. H. Bestor, "The DNA methyltransferases of mammals," Human Molecular Genetics, vol. 9, no. 16, pp. 2395-2402, 2000.
[95] E. Li, T. H. Bestor, and R. Jaenisch, "Targeted mutation of the DNA methyltransferase gene results in embryonic lethality," Cell, vol. 69, no. 6, pp. 915-926, 1992.

[96] H. Ji, L. I. R. Ehrlich, J. Seita et al., "Comprehensive methylome map of lineage commitment from haematopoietic progenitors," Nature, vol. 467, no. 7313, pp. 338-342, 2010.

[97] Y. Du, N. A. Jenkins, and N. G. Copeland, "Insertional mutagenesis identifies genes that promote the immortalization of primary bone marrow progenitor cells," Blood, vol. 106, no. 12, pp. 3932-3939, 2005.

[98] Y.-L. Hu, S. Fong, C. Ferrell, C. Largman, and W.-F. Shen, "HOXA9 modulates its oncogenic partner Meis1 to influence normal hematopoiesis," Molecular and Cellular Biology, vol. 29, no. 18, pp. 5181-5192, 2009.

[99] L. M. Pillay, A. M. Forrester, T. Erickson, J. N. Berman, and A. J. Waskiewicz, "The Hox cofactors Meisl and Pbx act upstream of gatal to regulate primitive hematopoiesis," Developmental Biology, vol. 340, no. 2, pp. 306-317, 2010.

[100] S. K. Gupta, M. Gupta, B. Hoffman, and D. A. Liebermann, "Hematopoietic cells from gadd45a-deficient and gadd45bdeficient mice exhibit impaired stress responses to acute stimulation with cytokines, myeloablation and inflammation," Oncogene, vol. 25, no. 40, pp. 5537-5546, 2006.

[101] S. J. Klebanoff, "Myeloperoxidase: friend and foe," Journal of Leukocyte Biology, vol. 77, no. 5, pp. 598-625, 2005.

[102] R. M. Kohli and Y. Zhang, "TET enzymes, TDG and the dynamics of DNA demethylation," Nature, vol. 502, no. 7472, pp. 472-479, 2013.

[103] J. J. Trowbridge, J. W. Snow, J. Kim, and S. H. Orkin, "DNA methyltransferase 1 is essential for and uniquely regulates hematopoietic stem and progenitor cells," Cell Stem Cell, vol. 5, no. 4, pp. 442-449, 2009.

[104] G. A. Challen, D. Sun, M. Jeong et al., "Dnmt3a is essential for hematopoietic stem cell differentiation," Nature Genetics, vol. 44, no. 1, pp. 23-31, 2012.

[105] G. A. Challen, D. Sun, A. Mayle et al., "Dnmt3a and Dnmt3b have overlapping and distinct functions in hematopoietic stem cells," Cell Stem Cell, vol. 15, no. 3, pp. 350-364, 2014.

[106] M. B. Bowie, K. D. McKnight, D. G. Kent, L. McCaffrey, P. A. Hoodless, and C. J. Eaves, "Hematopoietic stem cells proliferate until after birth and show a reversible phase-specific engraftment defect," The Journal of Clinical Investigation, vol. 116, no. 10, pp. 2808-2816, 2006.

[107] J. M. Nygren, D. Bryder, and S. E. W. Jacobsen, "Prolonged cell cycle transit is a defining and developmentally conserved hemopoietic stem cell property," The Journal of Immunology, vol. 177, no. 1, pp. 201-208, 2006.

[108] S. H. Cheshier, S. J. Morrison, X. Liao, and I. L. Weissman, "In vivo proliferation and cell cycle kinetics of long-term selfrenewing hematopoietic stem cells," Proceedings of the National Academy of Sciences of the United States of America, vol. 96, no. 6, pp. 3120-3125, 1999.

[109] M. J. Kiel, S. He, R. Ashkenazi et al., "Haematopoietic stem cells do not asymmetrically segregate chromosomes or retain BrdU," Nature, vol. 449, no. 7159, pp. 238-242, 2007.

[110] E. M. Pietras, M. R. Warr, and E. Passegué, "Cell cycle regulation in hematopoietic stem cells," Journal of Cell Biology, vol. 195, no. 5, pp. 709-720, 2011.

[111] E. Passegué, A. J. Wagers, S. Giuriato, W. C. Anderson, and I. L. Weissman, "Global analysis of proliferation and cell cycle gene expression in the regulation of hematopoietic stem and 
progenitor cell fates," Journal of Experimental Medicine, vol. 202, no. 11, pp. 1599-1611, 2005.

[112] V. Fantl, G. Stamp, A. Andrews, I. Rosewell, and C. Dickson, "Mice lacking cyclin D1 are small and show defects in eye and mammary gland development," Genes and Development, vol. 9, no. 19, pp. 2364-2372, 1995.

[113] M. Malumbres, R. Sotillo, D. Santamaría et al., "Mammalian cells cycle without the D-type cyclin-dependent kinases Cdk4 and Cdk6," Cell, vol. 118, no. 4, pp. 493-504, 2004.

[114] K. Kozar, M. A. Ciemerych, V. I. Rebel et al., "Mouse development and cell proliferation in the absence of D-cyclins," Cell, vol. 118, no. 4, pp. 477-491, 2004.

[115] E. Laurenti, C. Frelin, S. Xie et al., "CDK6 levels regulate quiescence exit in human hematopoietic stem cells," Cell Stem Cell, vol. 16, no. 3, pp. 302-313, 2014.

[116] R. Scheicher, A. Hoelbl-Kovacic, F. Bellutti et al., "CDK6 as a key regulator of hematopoietic and leukemic stem cell activation," Blood, vol. 125, no. 1, pp. 90-101, 2015.

[117] S. Yamazaki, A. Iwama, S.-I. Takayanagi et al., "Cytokine signals modulated via lipid rafts mimic niche signals and induce hibernation in hematopoietic stem cells," The EMBO Journal, vol. 25, no. 15, pp. 3515-3523, 2006.

[118] A. Matsumoto, S. Takeishi, T. Kanie et al., "P57 Is required for quiescence and maintenance of adult hematopoietic stem cells," Cell Stem Cell, vol. 9, no. 3, pp. 262-271, 2011.

[119] P. Zou, H. Yoshihara, K. Hosokawa et al., "P57 ${ }^{\text {Kip2 }}$ and $\mathrm{p} 27^{\mathrm{Kip} 1}$ cooperate to maintain hematopoietic stem cell quiescence through interactions with Hsc70," Cell Stem Cell, vol. 9, no. 3, pp. 247-261, 2011.

[120] T. Cheng, N. Rodrigues, D. Dombkowski, S. Stier, and D. T. Scadden, "Stem cell repopulation efficiency but not pool size is governed by p27 $7^{\mathrm{kipl}}$, Nature Medicine, vol. 6, no. 11, pp. 12351240, 2000.

[121] T. Cheng, N. Rodrigues, H. Shen et al., "Hematopoietic stem cell quiescence maintained by p21(cip1/waf1)," Science, vol. 287, no. 5459, pp. 1804-1809, 2000.

[122] I. Hidalgo, A. Herrera-Merchan, J. M. Ligos et al., "Ezhl is required for hematopoietic stem cell maintenance and prevents senescence-like cell cycle arrest," Cell Stem Cell, vol. 11, no. 5, pp. 649-662, 2012.

[123] V. Janzen, R. Forkert, H. E. Fleming et al., "Stem-cell ageing modified by the cyclin-dependent kinase inhibitor p16INK4a," Nature, vol. 443, no. 7110, pp. 421-426, 2006.

[124] J. L. Attema, C. J. H. Pronk, G. L. Norddahl, J. M. Nygren, and D. Bryder, "Hematopoietic stem cell ageing is uncoupled from p16 INK4A -mediated senescence," Oncogene, vol. 28, no. 22, pp. 2238-2243, 2009.

[125] M. Hilpert, C. Legrand, D. Bluteau et al., "p19 ${ }^{\mathrm{INK} 4 \mathrm{~d}}$ controls hematopoietic stem cells in a cell-autonomous manner during genotoxic stress and through the microenvironment during aging," Stem Cell Reports, vol. 3, no. 6, pp. 1085-1102, 2014.

[126] K. W. Orford and D. T. Scadden, "Deconstructing stem cell self-renewal: genetic insights into cell-cycle regulation," Nature Reviews Genetics, vol. 9, no. 2, pp. 115-128, 2008.

[127] K. Ito, A. Hirao, F. Arai et al., "Regulation of oxidative stress by ATM is required for self-renewal of haematopoietic stem cells," Nature, vol. 431, no. 7011, pp. 997-1002, 2004.

[128] A. Nijnik, L. Woodbine, C. Marchetti et al., "DNA repair is limiting for haematopoietic stem cells during ageing," Nature, vol. 447 , no. 7145, pp. 686-690, 2007.
[129] W. Wang, "Emergence of a DNA-damage response network consisting of Fanconi anaemia and BRCA proteins," Nature Reviews Genetics, vol. 8, no. 10, pp. 735-748, 2007.

[130] J. D. Down, A. Boudewijn, R. van Os, H. D. Thames, and R. E. Ploemacher, "Variations in radiation sensitivity and repair among different hematopoietic stem cell subsets following fractionated irradiation," Blood, vol. 86, no. 1, pp. 122-127, 1995.

[131] E. I. M. Meijne, R. J. M. van der Winden-van Groenewegen, R. E. Ploemacher, O. Vos, J. A. G. David, and R. Huiskamp, "The effects of $\mathrm{x}$-irradiation on hematopoietic stem cell compartments in the mouse," Experimental Hematology, vol. 19, no. 7, pp. 617-623, 1991.

[132] Z. Tothova, R. Kollipara, B. J. Huntly et al., "FoxOs are critical mediators of hematopoietic stem cell resistance to physiologic oxidative stress," Cell, vol. 128, no. 2, pp. 325-339, 2007.

[133] M. Milyavsky, O. I. Gan, M. Trottier et al., "A distinctive DNA damage response in human hematopoietic stem cells reveals an apoptosis-independent role for p53 in self-renewal," Cell Stem Cell, vol. 7, no. 2, pp. 186-197, 2010.

[134] J. Seoane, C. Pouponnot, P. Staller, M. Schader, M. Eilers, and J. Massagué, "TGF $\beta$ influences Myc, Miz-1 and Smad to control the CDK inhibitor p15INK4b," Nature Cell Biology, vol. 3, no. 4, pp. 400-408, 2001.

[135] K. H. Vousden, "Switching from life to death: the Miz-ing link between Myc and p53," Cancer Cell, vol. 2, no. 5, pp. 351-352, 2002.

[136] C. Kosan, I. Saba, M. Godmann et al., “Transcription factor miz1 is required to regulate interleukin-7 receptor signaling at early commitment stages of B cell differentiation," Immunity, vol. 33, no. 6, pp. 917-928, 2010.

[137] J. H. Patel and S. B. McMahon, "BCL2 is a downstream effector of MIZ-1 essential for blocking c-MYC-induced apoptosis," Journal of Biological Chemistry, vol. 282, no. 1, pp. 5-13, 2007.

[138] Y. Liu, S. E. Elf, Y. Miyata et al., "p53 regulates hematopoietic stem cell quiescence," Cell Stem Cell, vol. 4, no. 1, pp. 37-48, 2009.

[139] M. TeKippe, D. E. Harrison, and J. Chen, "Expansion of hematopoietic stem cell phenotype and activity in Trp53-null mice," Experimental Hematology, vol. 31, no. 6, pp. 521-527, 2003.

[140] A. A. Sablina, A. V. Budanov, G. V. Ilyinskaya, L. S. Agapova, J. E. Kravchenko, and P. M. Chumakov, "The antioxidant function of the p53 tumor suppressor," Nature Medicine, vol. 11, no. 12, pp. 1306-1313, 2005.

[141] D. J. Rossi, D. Bryder, J. M. Zahn et al., "Cell intrinsic alterations underlie hematopoietic stem cell aging," Proceedings of the National Academy of Sciences of the United States of America, vol. 102, no. 26, pp. 9194-9199, 2005.

[142] D. J. Rossi, C. H. M. Jamieson, and I. L. Weissman, "Stems cells and the pathways to aging and cancer," Cell, vol. 132, no. 4, pp. 681-696, 2008.

[143] V. P. Zediak, I. Maillard, and A. Bhandoola, "Multiple prethymic defects underlie age-related loss of T progenitor competence," Blood, vol. 110, no. 4, pp. 1161-1167, 2007.

[144] R. H. Cho, H. B. Sieburg, and C. E. Muller-Sieburg, "A new mechanism for the aging of hematopoietic stem cells: aging changes the clonal composition of the stem cell compartment but not individual stem cells," Blood, vol. 111, no. 12, pp. 55535561, 2008.

[145] B. Dykstra, S. Olthof, J. Schreuder, M. Ritsema, and G. D. Haan, "Clonal analysis reveals multiple functional defects of aged murine hematopoietic stem cells," The Journal of Experimental Medicine, vol. 208, no. 13, pp. 2691-2703, 2011. 
[146] D. J. Rossi, D. Bryder, J. Seita, A. Nussenzweig, J. Hoeijmakers, and I. L. Weissman, "Deficiencies in DNA damage repair limit the function of haematopoietic stem cells with age," Nature, vol. 447, no. 7145, pp. 725-729, 2007.

[147] K. L. Rudolph, S. Chang, H.-W. Lee et al., "Longevity, stress response, and cancer in aging telomerase-deficient mice," Cell, vol. 96, no. 5, pp. 701-712, 1999.

[148] S. Zimmermann and U. M. Martens, "Telomeres, senescence, and hematopoietic stem cells," Cell and Tissue Research, vol. 331, no. 1, pp. 79-90, 2008.

[149] J. Flach, S. T. Bakker, M. Mohrin et al., "Replication stress is a potent driver of functional decline in ageing haematopoietic stem cells," Nature, vol. 512, no. 7513, pp. 198-202, 2014.

[150] C. E. Rübe, A. Fricke, T. A. Widmann et al., "Accumulation of DNA damage in hematopoietic stem and progenitor cells during human aging," PLoS ONE, vol. 6, no. 3, Article ID e17487, 2011.

[151] M. Kim, H.-B. Moon, and G. J. Spangrude, "Major age-related changes of mouse hematopoietic stem/progenitor cells," Annals of the New York Academy of Sciences, vol. 996, pp. 195-208, 2003.

[152] D. Walter, A. Lier, A. Geiselhart et al., "Exit from dormancy provokes DNA-damage-induced attrition in haematopoietic stem cells," Nature, vol. 520, no. 7548, pp. 549-552, 2015.

[153] I. Beerman, J. Seita, M. A. Inlay, I. L. Weissman, and D. J. Rossi, "Quiescent hematopoietic stem cells accumulate DNA damage during aging that is repaired upon entry into cell cycle," Cell Stem Cell, vol. 15, no. 1, pp. 37-50, 2014.

[154] H. Geiger, G. de Haan, and M. C. Florian, "The ageing haematopoietic stem cell compartment," Nature Reviews Immunology, vol. 13, no. 5, pp. 376-389, 2013.

[155] W. W. Pang, E. A. Price, D. Sahoo et al., "Human bone marrow hematopoietic stem cells are increased in frequency and myeloid-biased with age," Proceedings of the National Academy of Sciences of the United States of America, vol. 108, no. 50, pp. 20012-20017, 2011. 

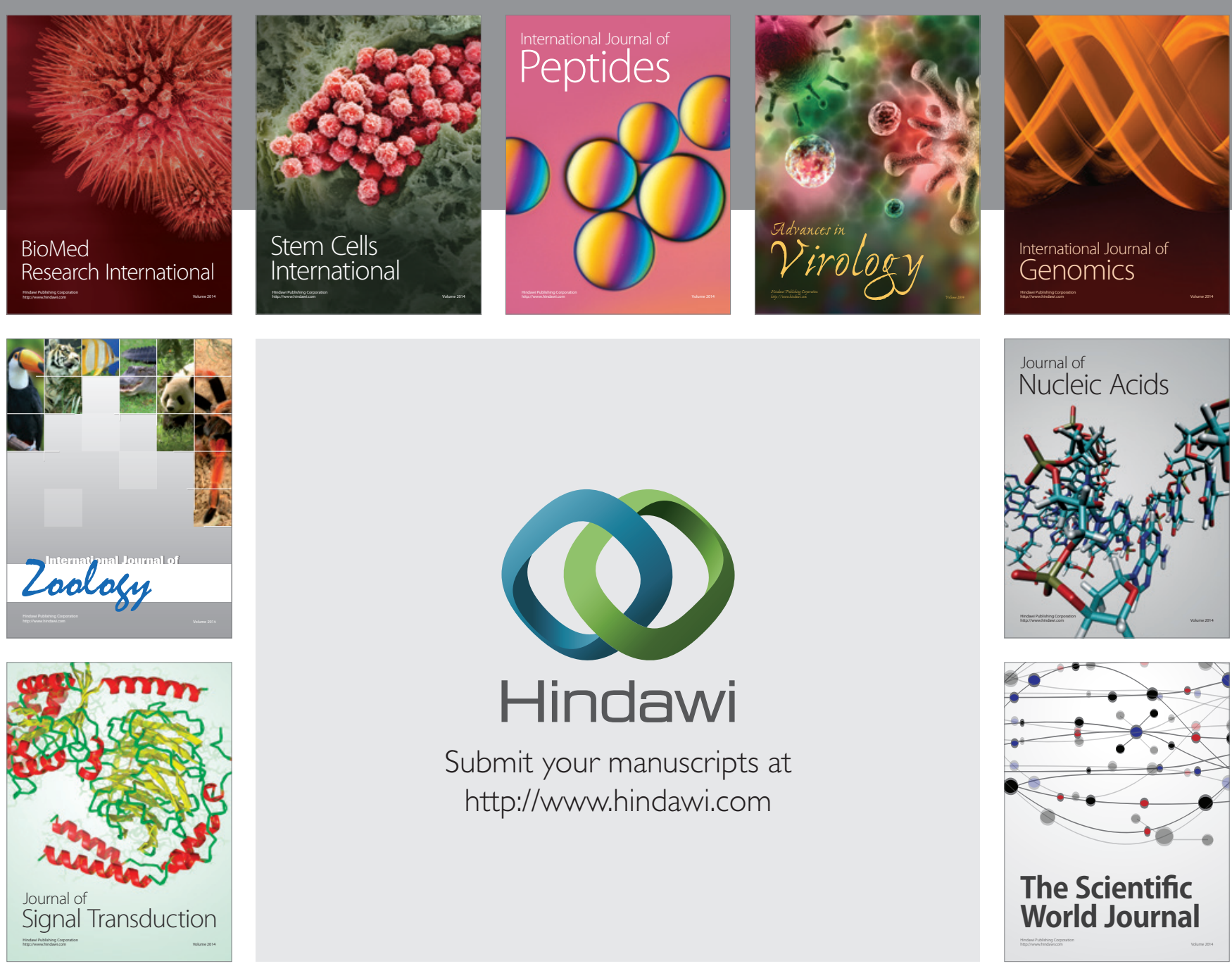

Submit your manuscripts at

http://www.hindawi.com
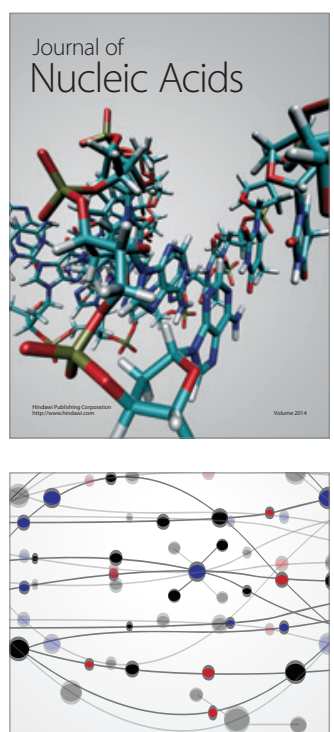

The Scientific World Journal
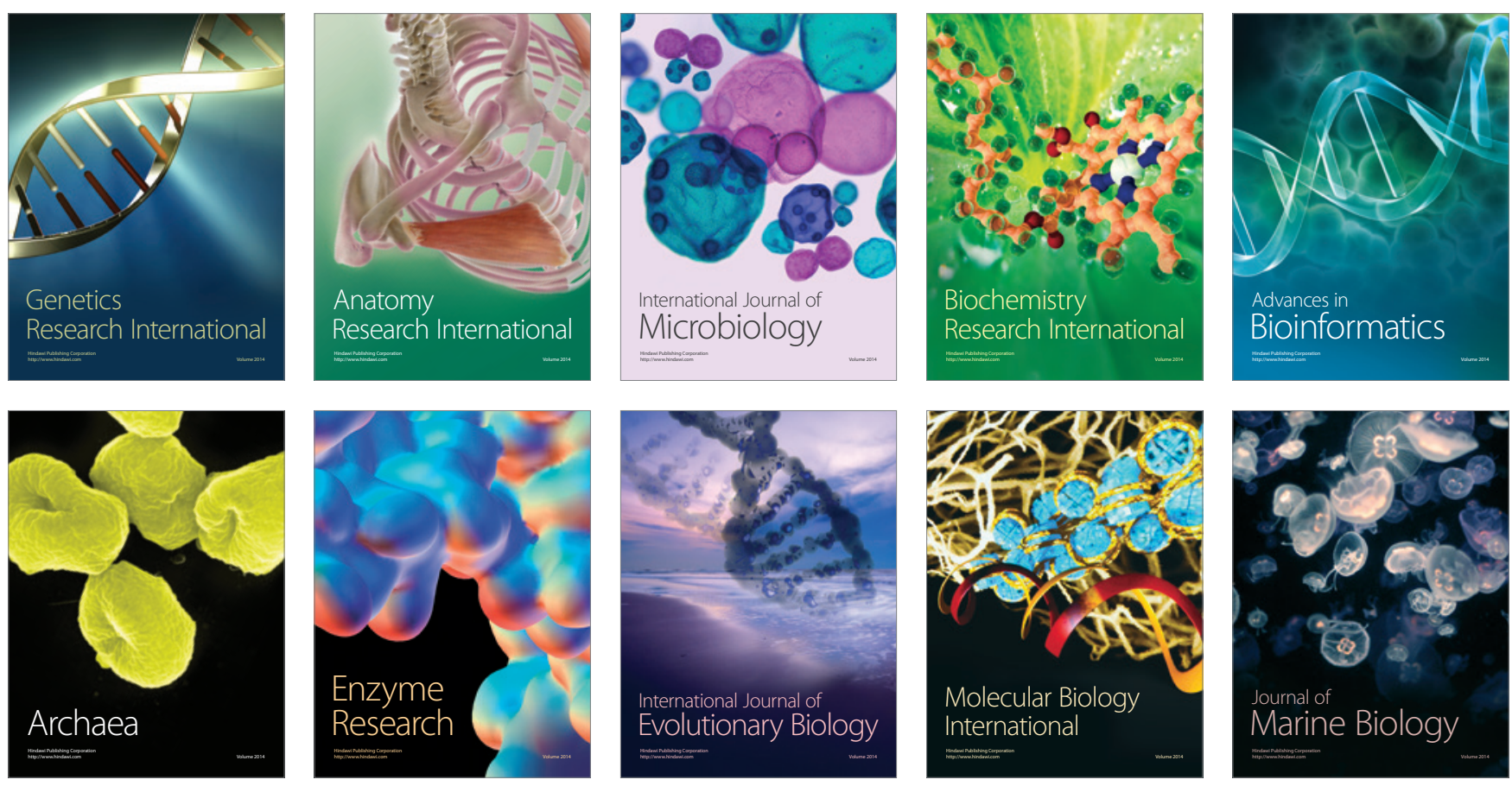